\title{
'Phalap-Khah' - the bitter tea of Tangsa community in the Changlang district of Arunachal Pradesh, India
}

\author{
P. Lungphi, A. V. Singh ${ }^{1}$ and A. P. Das \\ Department of Botany, Rajiv Gandhi University, Rono Hills, Doimukh 791112, Arunachal Pradesh, India \\ ${ }^{1}$ Corresponding author: victor_ayamsingh@yahoo.com
}

[Received 12.05.2019; Revised \& accepted 20.06.2019; Published 30.06.2019]

\begin{abstract}
Tangsa community of Changlang district of Arunachal Pradesh, India, practices a unique tea processing technique producing a traditional tea product locally known as 'Phalap' or 'Felap' for daily consumption and they believe it to be anti-cancerous and anti-diabetic. A field survey and interview on the age old Phalap preparation was conducted from the local people using semi-structured questionnaire. It was found that Phalap was in use by Tangsa since their unknown past and is found to be mentioned even in their folklores. The detail methods for processing of Phalap has been reflected in this article.
\end{abstract}

Key words: Phalap-Khah, Tangsa community, Processing, Folklore and history

\section{INTRODUCTION}

The tea plant, Camellia sinensis (L.) Kuntze (Theaceae) was first used in China during the Chang dynasty around $2737 \mathrm{BC}$ when it was accidentally recognised as a potent medicinal plant (Kabir \& Das 2015). In course of time tea become popular as a beverage. This tea culture gradually crossed the limits of Chinese territory and is now became the most preferred beverage. Documentary evidence dating back to $350 \mathrm{BC}$ prove that tea had its origins in China. But, it is also speculated that tea is being consumed in India as well, may be in different forms. Contrary to the popular conception, tea was not really an "imported/foreign" crop, but is an indigenous plant of India. Tea has been an integral part of social culture and medicine for at least 900 years in different parts of India, Myanmar \& China [https:// www.tealeaftheory.com/tribal-n-traditional-tea/singpho-tea/singpho-falap-4-years-smokedbamboo-tea-/37/].

The tea plant was named as Thea sinensis in 1753 by Carolus Linnaeus in his famous Species Plantarum. Later on, O. Kuntze transferred the species to the genus Camellia and now Camellia sinensis is the accepted name along with its three taxonomic varieties, namely: C. sinensis (L.) Kuntze var. sinensis; $C$. sinensis var. assamica (J.W. Mast.) Kitam. and C. sinensis var. lasiocalyx (Watt) A.P. Das \& C. Ghosh (Das \& Ghosh 2016; Kabir \& Ghosh 2018). These three varieties are commonly referred as 'China variety', 'Assam variety' and 'Cambod variety', respectively (Kabir \& Ghosh 2018).

The tea is now cultivated in many countries including India, which is the second largest tea producer but produce best quality naturally aromatic tea. However, this naturally aromatic tea is produced from the plants those were basically introduced from China, i.e. Chinavariety tea plants (Camellia sisnensis var. sinensis). Later on naturally occurring tea plants were spotted in the then Lakhimpur sector (now in Tinsukia district) of Assam. This plant is 
34 Phalap-Khah of Tangsa community in Changlang district

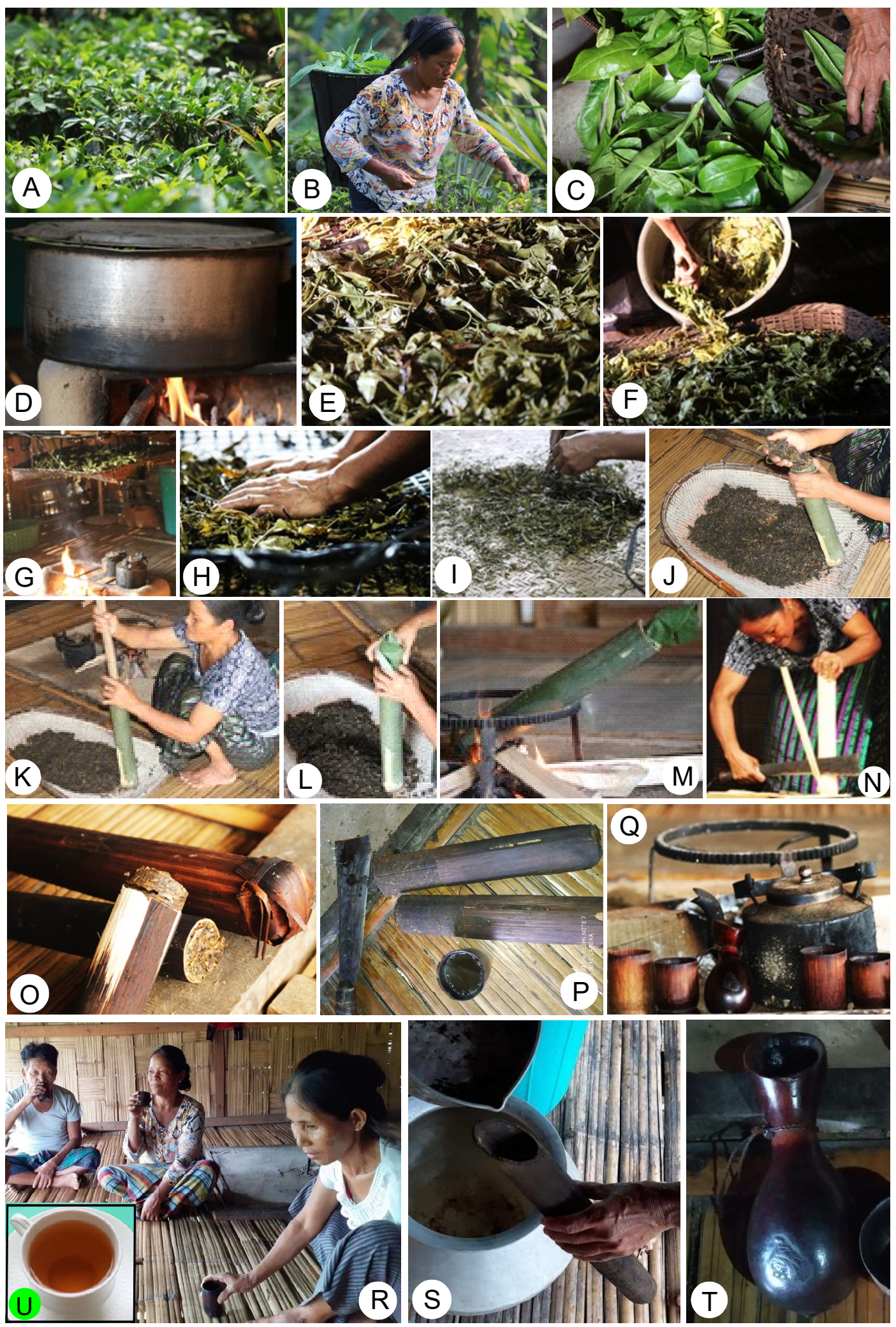




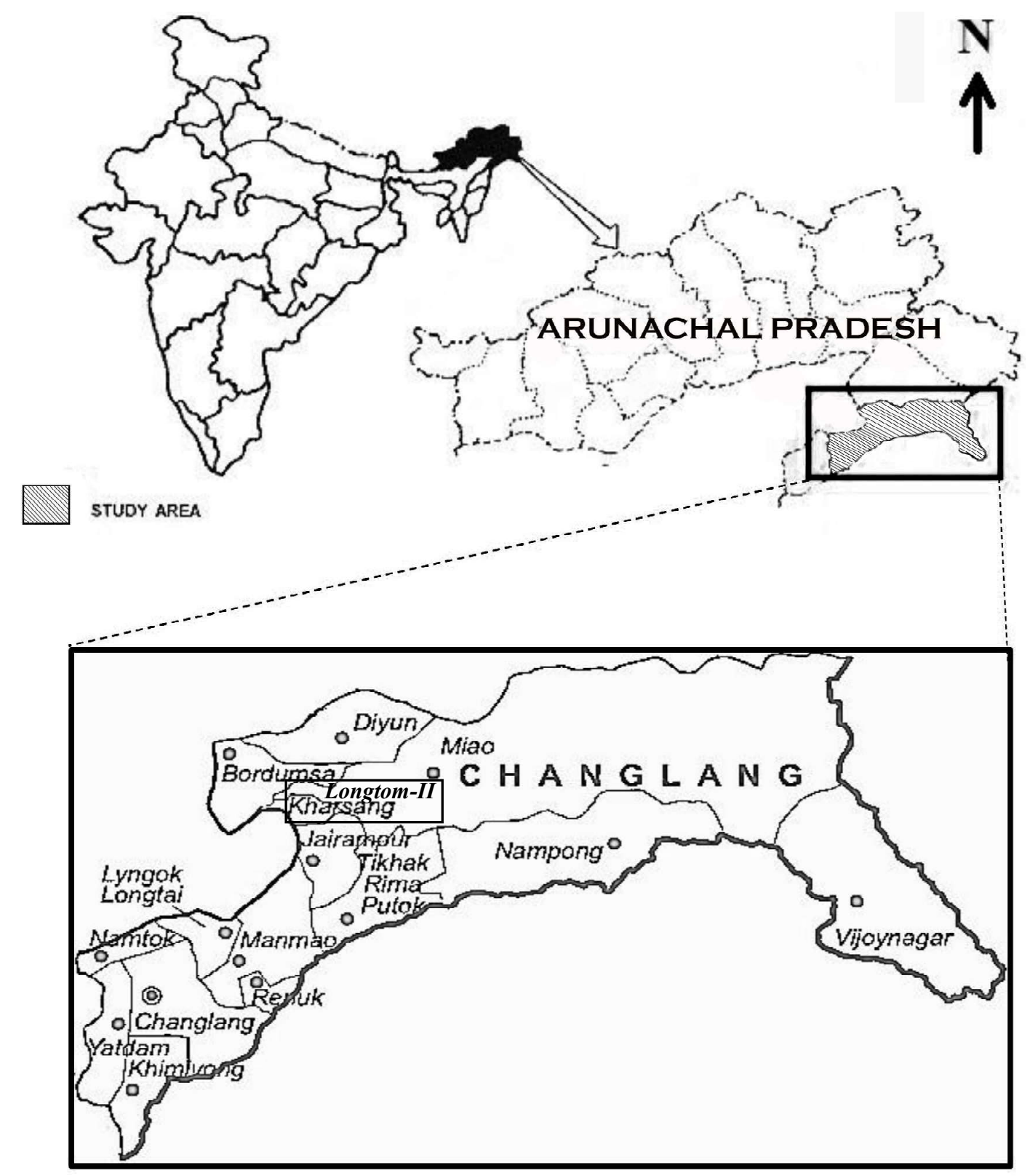

MAP - 1. Location of the study area - Longtom-II village in Kharsang Circle of Changlang district

Legends for: Page 34: PLATE - I. Phalap preparation by Tangsa community: A. Part of small Tea Garden; B. Plucking tea twigs; C. Taking harvest in a 'Mokhang'; D. Heating over a fire-place; E. Discoloured tea-leaves; F. Transferred to a 'Phey'; G. Hanging over the fire-place; H. Breaking dry leaves manually on a 'daam'; I. Large fragments isolated for further drying; J. Filling of bamboo-tube; K. Making the content compact with a piece of wood; L. Temporary plugging by Macaranga denticulata leaves; M. Heating bamboo tube in fire-place; N. Trimming outer layers of bamboo tube with a 'jang' when heating process is over; $\mathbf{O} \& \mathbf{P}$. Final product - bamboo-wall partially removed to cut phalap; Q. Cattle to brew phalap and bamboo-cups; R. Family members enjoing 'phalap-khah'; S. Phalap may also be brewed in bamboo-tubes; T. Carry phalap in fruit-shell of Lagenaria siceraria for drinking; U. Golden-brown tea when brewed like orthodox black-tea. 
slightly different from Chinese population and is scientifically recognised as Camellia sinensis var. assamica (J.W. Mast.) Kitam., - that is now occupying the major share of land under tea cultivation in India (Kabir \& Das 2015).

Tangsa is a community of people living mostly in some small areas in Myanmar and in the Changlang district of Arunachal Pradesh in India. These people are habituated to consume good amount of strong (bitter) tea throughout the day. Tangsas probably left their Chinese settlement area long back, entered Myanmar and then came to India and are now living mostly on Paktkai hill range extensions in Arunachal Pradesh. Few of them are also living in the hilly areas of Tinsukia district of Assam, bordering Arunachal Pradesh (Lungphi et al. 2018).

From the time, actually unknown to them, Tangsas are processing tea leaves following their traditional methodology leading to a completely different type of product that is generally referred as 'Phalap' or 'Felap'. They love to consume Phalap in good amount, especially after the meals and believe that it helps in digestion and keeps the community relatively free from cancer and diabetes. Another community, 'Singpho' also produce and use Phalap almost in the similar manner [https://www.tealeaftheory.com/tribal-n-traditional-tea/singphotea/singpho-falap-4-years-smoked-bamboo-tea-/37/]. This product is completely different from the 'Orthodox' and 'CTC' (Crushing Tearing \& Curling) tea-types of commerce as produced by all Tea Gardens. The present article deals with the detail investigation on the age old Phalak tea preparation on Tangsa tradition.

\section{MATERIALS AND METHODS}

Study Community: The Sino-Burmese community 'Tangsa' is living in some districts of Arunachal Pradesh bordering Myanmar and in Assam. However, they are also living in areas of Myanmar on the other side of Indian border. They are native to India (Arunachal Pradesh) and Myanmar (Hkamti, Myitkyina districts), living mostly in remote areas and settled mainly in the extensions on Patkai Mountain ranges and some live in plain areas (Simai, 2008; https:// en.wikipedia.org/wiki/Tangsa_people). Tangsa people believe that they migrated from an area what is now Mongolia, through the Yunan Province of South-West China and then to Myanmar. From Myanmar they then moved to Arunachal Pradesh in India in search of better habitable areas and food production. Tangsa folklores suggest that they settled in their present areas of distribution in the beginning of $13^{\text {th }}$ century (Rao 2006; Simai 2008).

Tangsas have very rich Traditional Knowledge on plants and that is yet to be recorded scientifically. As the present educated generation is now engaged in different services in the outer world and coming under the influences of the modern civilization and its products, they are now more inclined to industrial products rather than their traditional items of living. So, with the progress of the benefits of modern civilization and the easy availability of industry made commodities, soon, the people of the future generations will lose their interest in carrying their Traditional Knowledge and that will lead to the loss of so important age-old stock of knowledge. So far, almost no ethnobotanical study was conducted on these people except a small work covering only one village of Changlang district (Lungphi et al. 2018).

Study Area: Changlang district $\left[26^{\circ} 40^{\prime} \mathrm{N}\right.$ to $27^{\circ} 40^{\prime} \mathrm{N}$ Latitude and $95^{\circ} 11^{\prime} \mathrm{E}$ to $97^{\circ} 10^{\prime} \mathrm{E}$ Longitude] is located in the south-eastern corner of the state, is covers with picturesque hills of Patkai Range (Map 1). It is bounded by the Tinsukia district of Assam and Lohit district of Arunachal Pradesh in the north; Tirap district in the west and Myanmar in the south-east. The district covers an area of $4662 \mathrm{sq} \mathrm{km}$ with a population of 1,48,226 according to the 2011 census report (Anonymous, 2014) and is mostly inhabited by the Tangsas. Few other tribes, 
including Singpho, Tutsa and Lisu (Yobin) are also living in the district. The altitude varies from $200 \mathrm{~m}$ to $4500 \mathrm{~m}$ AMSL. January is the coldest month and the average minimum and maximum temperature ranges from $13^{\circ} \mathrm{C}$ and $22^{\circ} \mathrm{C}$ respectively. August is the hottest month and temperature may occasionally exceed $30^{\circ} \mathrm{C}$. Rainfall is also very much influenced by the terrain and the annual rainfall ranges from $3800 \mathrm{~mm}$ to $4866 \mathrm{~mm}$. The maximum rainfall is received during the months of June through October. As much as $92.36 \%$ of the total area of Changlang district is with forest cover (FSI 2011).

Methodology: Major part of the study was conducted in the Longtom-II village in the Kharsang circle of Changlang district. Mrs. Namlong Lungphi regularly produce Phalap [or Felap] in good amount. She demonstrated the entire procedure in her tea-garden and in the house. Different steps of the entire process has been recorded in the Field Note Book and also in sequential photography.

Different information regarding Phalap was collected from local people using semi-structured questionnaire. Mandatory PIC was taken from after explaining our work in Tangsa language. The first author (PL) being a Tangsa, it was very helpful to communicate and conduct the work.

\section{OBSERVATION}

Mrs. Namlong Lungphi prepare Phalap throughout the year. The basic material used for Phalap preparation is freshly collected young tea-twigs. [Plate I]

Gardening: Tea plants (local Assam variety; Camellia sinensis var. assamica) are grown in small gardens and are generally trimmed to maintain a short height and that also helps to produce numerous new branches. But, these gardens, trimming and maintenance are not similar to large tea plantations for orthodox or CTC tea. No pesticide or fertilizer is added for better growth and these plants generally remain healthy and diseases and pests are quite rare.

Plucking: Only fast-growing new shoots with up to four soft young leaves are plucked. Stem part attached to these young leaves are not rejected.

Heat treatment: Freshly collected twigs are transferred in a 'Mokhang' or 'Dekchi' kept over the flame and stirred continuously until the twigs become soft and discoloured (chlorophylls denatured).

Drying: Materials are then transferred on a 'Phey' [spaced bamboo mat with raised margins] and spread evenly. The Phey is then kept hanging about $120 \mathrm{~cm}$ above the fire place. It takes about 24 hours for drying. Some people dry the leaves under sun but people always preferred the smoked ones.

Cutting: Dry twigs are then taken on 'Daam' [close-set flat bamboo mat] and softly crushed on it by hand. Only well-dried ones will be broken into small fragments. Less dried ones will be back to the Phey for further drying.

Bamboo container: A freshly cut green bamboo is made in to pieces with one node and one full internode. Dry bamboos are not suitable as those produce unfavourable aroma and possibility of catching fire easily during heating/ roasting.

Stuffing \& Roasting: The dry and fragmented tea is now put into the whole of bamboocontainer and stuffed compact with a slender piece of wood [may be a piece of dry branch]. Close-end of the stuffed bamboo-container is then places directly in fire and that lead to the further compaction and creates some empty space. More leaves are then pushed again inside, roasted again and the process is continued till the container is completely filled and 
content becomes almost solid. During this process, leaves of Chahhao-jaak (Macaranga denticulata (Blume) Müll. Arg.) are used as temporary lid for the bamboo-container. When the container is full the mouth is then tightly closed by thin, flat and broad bamboo-slips before final roasting. The content is dry but become solid and needs weapon (mainly 'daao' or 'jang') to break/ cut it.

Thinning of container wall: After the completion of roasting process, the outer wall of the bamboo container is scrapped slowly and only a thin layer of bamboo-tissue is retained. This will facilitate the use of Phalap as the thin and roasted bamboo tissue-layer can be broken and removed quite easily.

Storing: When the satisfactory level of roasting is achieved then those can be stored for $8-$ 10 years in dry and warm places but it produce best results in $4^{\text {th }} \& 5^{\text {th }}$ year after production [https://www.tealeaftheory.com/tribal-n-traditional-tea/singpho-tea/singpho-falap-4-yearssmoked-bamboo-tea-/37/]. Generally they store it on 'Kharang', a storey or loft made over the fire place where they store many other important materials including dry meat. In photo the surface looks burnt that is produced due to its exposure to smoke of the fireplace that remains active for most part of the day.

Marketing: Phalap is also marketed locally and those who can't share enough time to prepare it they procure it from market. The weight of one piece of Phalap is around $1 \mathrm{~kg}$ and is sold in Rs.200-250. So far its marketing outside Tangsa and Singpho inhabiting areas is not known.

\section{Making tea for drinking:}

Tangsa people love to drink good amount of tea every day. Bamboo layer from some upper part is removed. About 50-70 gm of the solid Phalap is cut using a daao or jang (simple multipurpose cutting equipment made of iron). It is then made into small pieces and added to about 1.5 litter of boiling water in a kettle that is kept on the fire-place. After adding the Phalap, it is then boiled for $15-30$ minutes until it become Khah (=bitter). They love to sip bitter tea and do not use any additives (i.e. without milk, sugar, salt or butter). The intensity of the brownness of the liquor varies with amount of Phalap and the period of boiling. However, they also brew phalap traditionally in bamboo-tubes.

Generally they take tea in bamboo-cups made from young bamboo-culm. Sometimes they carry brewed phalap in Lagenaria siceraria (Molina) Standl. fruit-shell, with a filter of Luffa cylindrica (L.) M.Roem. fibrous mesocarp at the neck, to drink it slowly.

For those who are habituated to take orthodox leaf tea (not CTC) for them Phalap will be much bitter and strong. However, CTC tea is generally boiled. In orthodox tea sometimes a burnt or smoky smell is available that is due to some faulty processing (over firing) and is treated as a non-deserving character. But, in Phalap, the smoky smell is produced due to processing where it is roasted as a part of processing and is also stored in highly smoky environment and a deserving character.

In their Phalap-Khah (bitter tea) they never add any sugar or salt or milk. However, if the Phalap is brewed like orthodox tea, i.e. without boiling and just brewed in pre-boiled water, it produce a light to moderately brownish or a golden-orange tea, non-bitter, smokesmelling but with appreciable taste.

\section{DISCUSSION}

Phalap-khah is an integral part of life for Tangsa people. Almost everybody love to consume it whenever they feel. Generally they start taking Phalap-khah at quite young age, 15-16 
years old and by both boys and girls, and continue to take it throughout their life. Often, younger children are not allowed to drink it.

Every day, before going out for day's work, they take a heavy meal in the morning and, after that they consume good amount of Phalap-khah. They take this after the morning meal that is generally during 6-7-30 am. Drinking Phalap-khah refresh their mind, feels energetic and that help them to work for a long time.

Many people procure it from the market but the buyers are only Tangsas and Singphos. It is now essential to show-cased it properly in other areas so that it become popular in the outside world and can help to develop an industry for its manufacture.

Assam variety of tea is a local plant and was collected first from the nearby region in Assam. The Materials for the Flora of Arunachal Pradesh (Hajra et al. 1996) recorded the occurrence of five wild species of Camellia L. [C. caudata Wall.; C. kissii Wall.; C. lutescens Dyer; C. siangensis T.K. Paul \& M.P.Nayar; C. sinenensis (L.) Kuntze] for Arunachal Pradesh. At the same time there are 97 species of Camellia growing in different parts of China [http://www.efloras.org/florataxon.aspx? flora_id=2\&taxon_id=105380]. So, wild species of Camellia are present in the distantpast and the present homeland of Tangsas. Even when inquired with the senior-most people of the area, they used Phalap from their childhood and was nothing new for them. It is now essential to know the tea-habit of the people in Mongolia. But, there they prepare tea with milk and that is almost similar to Tibetan tea (Bamana 2015). Social implication of tea in Mongolia (Bamana 2015) and in Changlang are also quite different. So, the tea habit is not connecting Tangsas with Mongolia. May be, the entire community was migrated out and are maintaining their own heritage and tradition in their present settlements. Or, they might have developed this technology themselves after their departure from Mongolia.

\section{CONCLUSION}

Phalap-khah is the 'heritage' product of the Tangsa (also may be of Singphos) people as they are producing and using it since their unknown past and is mentioned in their folklores. But, some basic researches are essential to know the biochemical properties of Phalap before taking any step for its marketing in outside world.

\section{Acknowledgements}

Authors are grateful to Mrs. Namlong Lungphi and Mrs. Jinmya Lungphi of Longtom-II village for their kind demonstration of the entire procedure, both outdoor and indoor activities. They are also thankful to the senior people of Longtom-II and of nearby villages for sharing their views on Phalap-Khah.

\section{LITERATURE CITED}

Anonymous, 2014. Census of India 2011, Arunachal Pradesh : District Census Handbook Changlang [Series 13; Part XIIA]. Directorate of Census Operations, Arunachal Pradesh.

Bamana, G. 2015. Tea Practices in Mongolia: A Field of Female Power and Gendered Meanings. Asian Ethnology, 74(1): 193 - 214.

Das, A.P. \& Ghosh, C. 2016. Camellia sinensis var. lasiocalyx (Watt) A.P. Das \& C. Ghosh, comb. nov. for the Cambod variety of tea. Pleione 10(1): $167-168$.

FSI 2011. India State Forest Report 2011. Forest Survey of India, Dehra Dun. 
40

Phalap-Khah of Tangsa community in Changlang district

Hajra, P.K.; Verma, D.M. \& Giri, G.S. 1996. Materials for the Flora of Arunachal Pradesh. Vol. I. Botanical Survey of India, Calcutta.

http://www.efloras.org/florataxon.aspx?flora_id=2\&taxon_id=105380 [FOC Vol. 12 Pages $366-367$

https://www.tealeaftheory.com/tribal-n-traditional-tea/singpho-tea/singpho-falap-4-yearssmoked-bamboo-tea-/37/

https://en.wikipedia.org/wiki/Tangsa_people

Lungphi, P.; Wangpan, T. \& Tangjang, S. 2018. Wild edible plants and their additional uses by the Tangsa community living in the Changlang district of Arunachal Pradesh, India. Pleione 12(2): 151 - 164

Kabir, S.E. \& Das, A.P. 2015. Tea Cultivation in the Plains of North East India. Regency Publications, a division of Astral International (P) Ltd., New Delhi.

Kabir, S.E. \& Ghosh, C. 2018. Tea cultivation in the Indian Himalayan region. In: Das, A.P. \& Bera, S., Floristic Diversity in the Himalaya Hotspot Region. Vol. 2. M/s Bishen Singh Mahendra Pal Singh, Dehra Dun [ISBN: 978-81-211-0985-7]. Pp. 743 - 767.

Rao, N.S. 2006. Tribal Culture, Faith, History and Literature. Mittal Publication, New Delhi.

Simai, C. 2008. A profile of the Tikhak Tangsa tribe of Arunachal Pradesh. Author's Press, New Delhi. 